\title{
The Relationship Between Musculoskeletal Injuries and Stress Load in Emergency Medical Staff of Hamadan Province in 2019
}

\author{
Mohamad Mehdi Sahraei ${ }^{1}$, Mehdi Molavi Verdanjani², Alireza Soltanian ${ }^{3}$, Mahnaz Khatiban ${ }^{*}$
}

1. M.Sc. Student, Department of Nursing, School of Nursing and Midwifery, Hamadan University of Medical Sciences, Hamadan, Iran

2. Instructor, School of Nursing and Midwifery, Hamadan University of Medical Sciences, Hamadan, Iran

3. Professor, Department of Biostatistics and Epidemiology, School of Health, Hamadan University of Medical Sciences, Hamadan, Iran

4. Professor, Mother and Child Care Research Centre, Dept. of Ethics Education in Medical Sciences, and Dept. of Medical-Surgical Nursing, School of Nursing and Midwifery School, Hamadan University of Medical Sciences, Hamadan, Iran

Article Info
Received: $2019 / 12 / 28$
Accepted: $2020 / 04 / 29 ;$
Published Online: $2020 / 10 / 11$
doi $10.30699 /$ ajnmc.29.1.23
Original Article
Use your device to scan
and read the article online
D.

\section{ABSTRACT}

Introduction: Emergency medical staff who are at the forefront of health care delivery face many occupational stresses that have psychological, physical, behavioral, and organizational consequences for them, including musculoskeletal disorders. The purpose of this study was to investigate the correlation between musculoskeletal injuries and stress load tolerance among medical emergency staffs in Hamedan province.

Methods: In this descriptive-correlational study, conducted in 2019, 76 (40\%) of urban and $114(60 \%)$ of employees of road bases were selected from among emergency medical staff of Hamadan, Iran. Data were collected using Nordic Musculoskeletal Injury Questionnaire and Occupational Stress Questionnaire. Data were analyzed by SPSS 23 using descriptive statistics, t-test and Spearman correlation coefficient.

Results: The mean age of the participants was $34.05( \pm 8.11)$ years and the work experience was $123.42( \pm 84.22)$ months. The majority (77\%) were married, 57.3\% had undergraduate degrees and $46.9 \%$ had formal employment. Employee stress burden was $503.3(161.23 \%)$ out of 1050 points. Persons who had musculoskeletal disorder due to their job had reported more stress than others; hoever, this difference was not significant $(P<0.05)$. People with musculoskeletal disorders in neck reported higher stress load $(P<0.05)$ than others which was not significant. There was a significant relationship between type of employment, work experience, and type of exercise with musculoskeletal disorders $(P<0.05)$.

Conclusion: There was a significant relationship only between stress and musculoskeletal damage. By modifying and eliminating stressors in emergency personnel's routines, by holding workshops on ergonomic principles as well as stress reduction principles, it is possible to reduce the physical disorders of emergency personnel.

Keywords: Occupational Stress, Musculoskeletal Injury, Medical Emergency

Mahnaz Khatiban, Professor, Mother and Child Care Research Centre, Dept. of Ethics Education in Medical
Sciences, and Dept. of Medical-Surgical Nursing, School of Nursing and Midwifery School, Hamadan University

Corresponding Information: of Medical Sciences. Hamadan. Iran. Email: mahnaz.khatiban@omail.com

Copyright $(C 2021$, This is an original open-access article distributed under the terms of the Creative Commons Attribution-noncommercial 4.0 International License which permits copy and redistribution of the material just in noncommercial usages with proper citation.

How to Cite This Article:

Sahraei M M, Molavi Verdanjani M, Soltanian A, Khatiban M. The Relationship between Occupational Stress and Musculoskeletal Disorders in Emergency Medical Staff. Avicenna J Nurs Midwifery Care. 2020; 29 (1) :23-34 
بررسى ارتباط آسيبهاى عضلانى - اسكلتى و بار استرس در كاركنان فوريت يزشكى استان در سال 19+r محمدمهدى صحر ايى'، مهدى مولوى وردنجانى '، عليرضا سلطانيان"، مهناز خطيبان "*

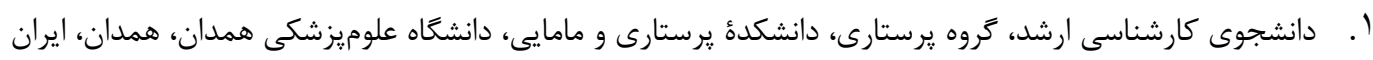

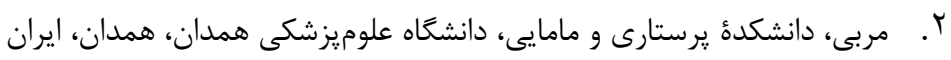

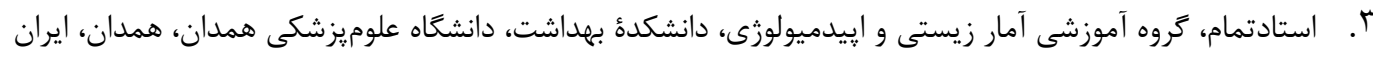

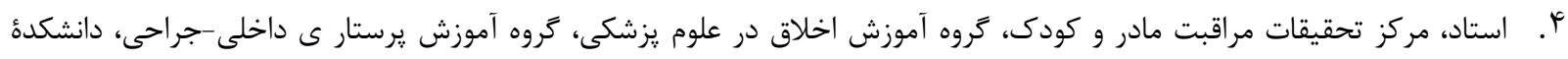

$$
\begin{aligned}
& \text { يرستارى و مامايى، دانشخاه علوم يزشكى همدان، همدان، ايران }
\end{aligned}
$$

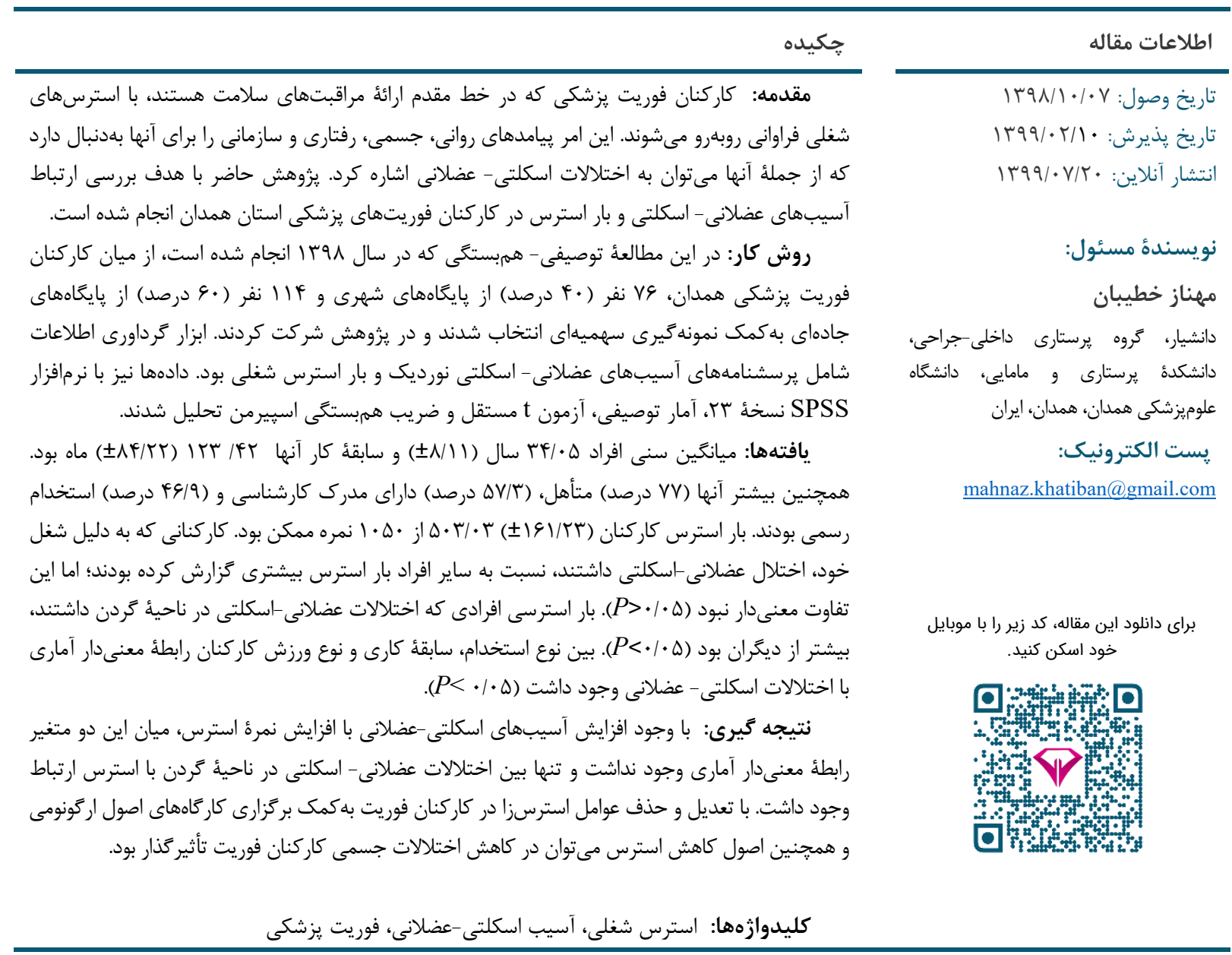

مراقبتهاى يِيشبيمارستانى شامل مراقبتهايى است كه از

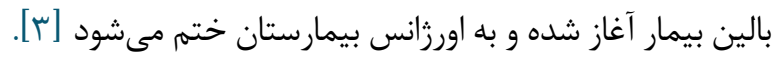

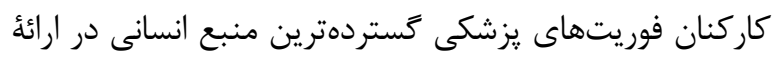

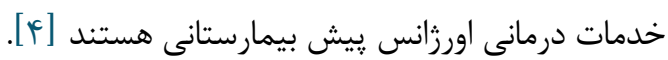

\footnotetext{
1. Emergency Medical Service
}

اورزانس پيشبيمارستانى' بخش مهمى از سيستم ارائٔ

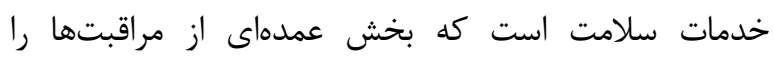

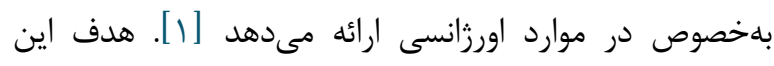
خدمات يزشكى، فراهمكردن درمان مناسب در محل و زمان

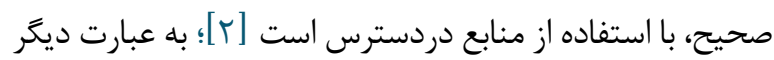




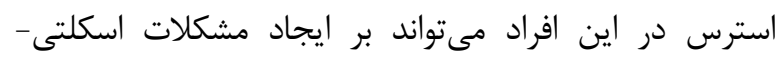

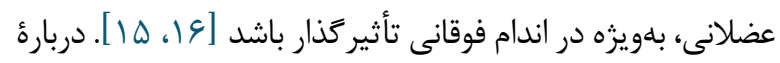

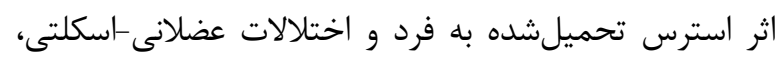

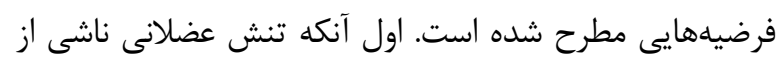

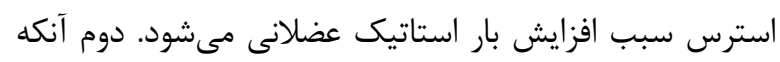

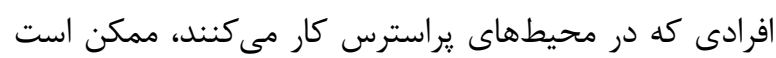

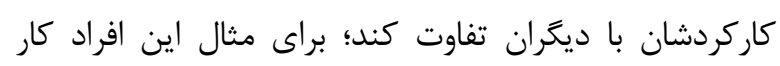

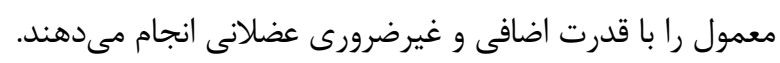

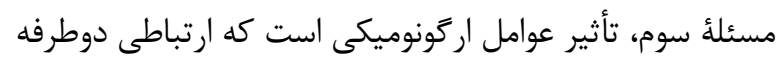

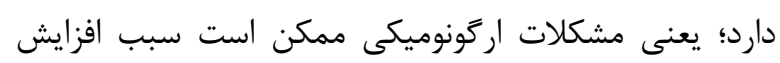

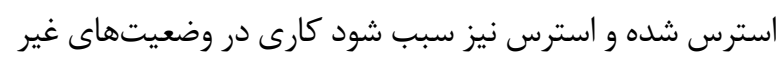

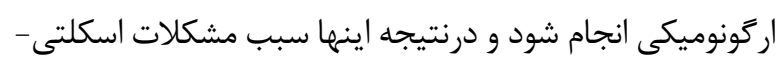

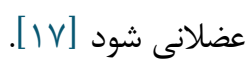
اختلالات اسكلتى- عضلانى به هركونه آسيب بافتى به

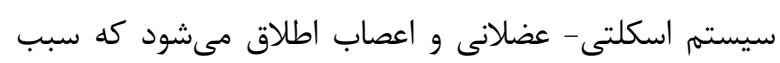

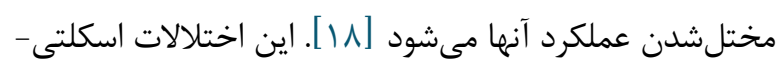

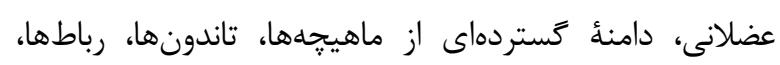

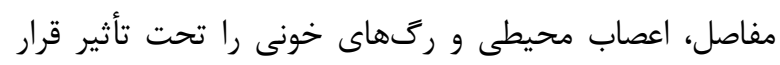

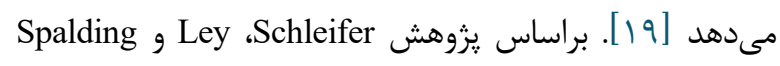

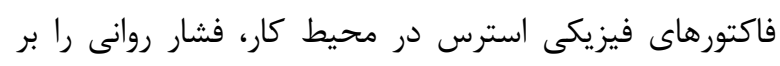

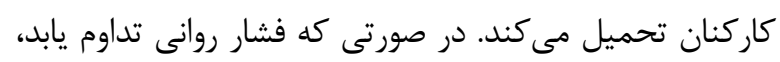

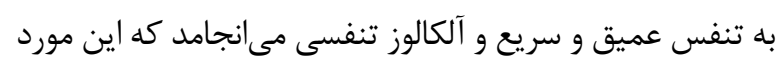
سبب تحريك سيستم عصبى و ايجاد تنش، فشار و و اسياسم

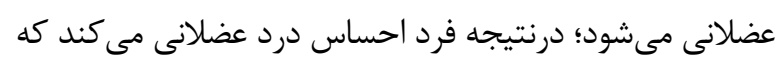

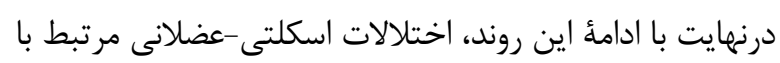

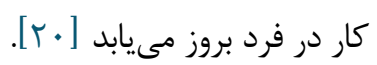
تاكنون در برخى مطالعات به بررسى ارتباط اختلاتلاتلات

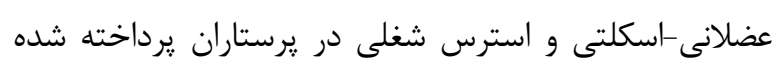

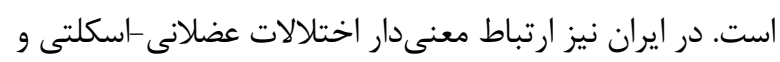

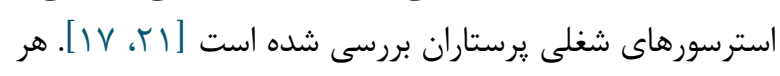

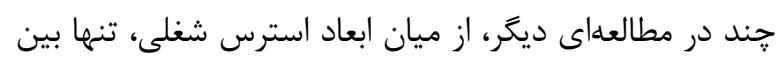

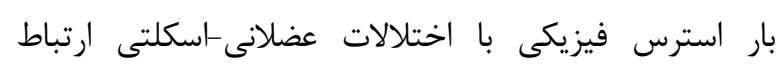

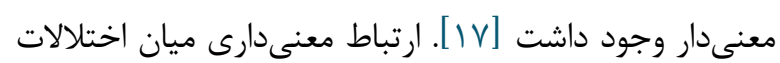

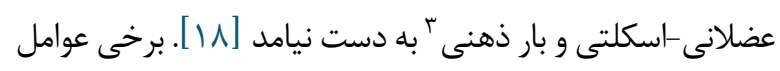

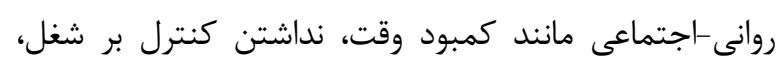
رضايت كم شغلى، نداشتن حمايت و امنيت در محل كار بر ايجاد

3. Mental load

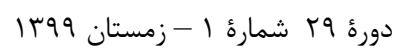

كاركنان فوريتهاى يزشكى بنا به ماهيت خاص شغل خود،

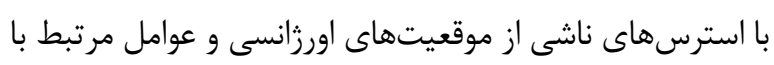

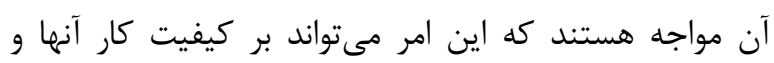

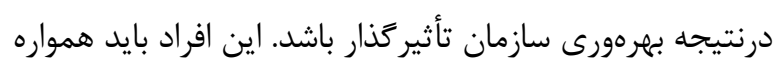

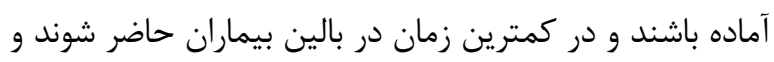

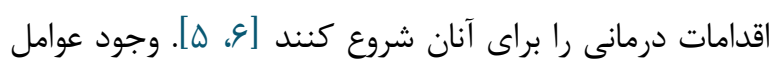

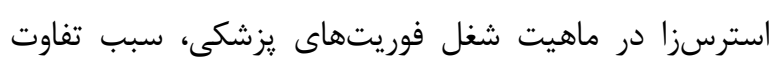

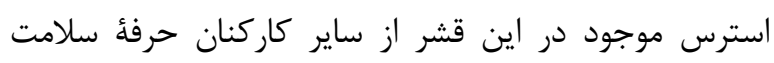

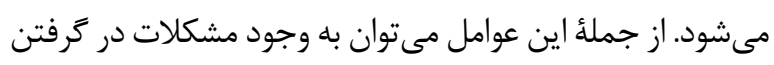

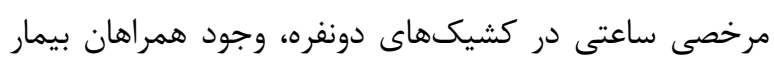

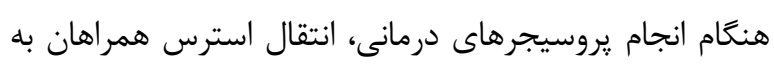

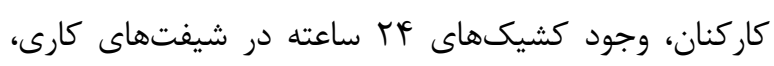

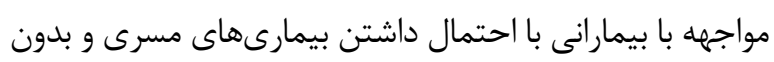

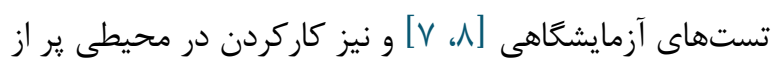

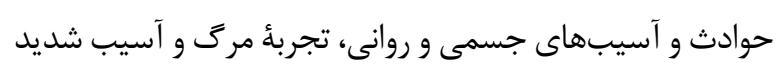

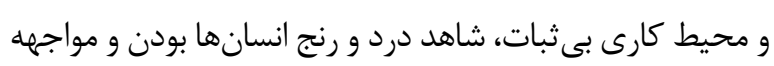

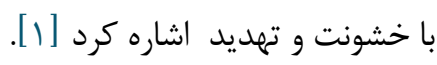

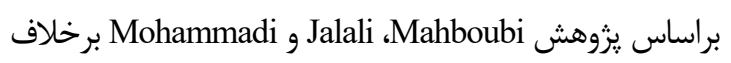

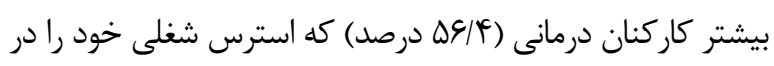

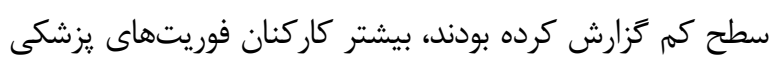

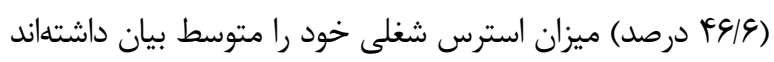

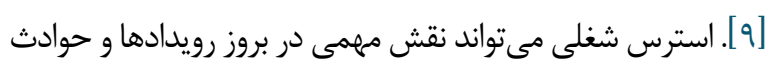

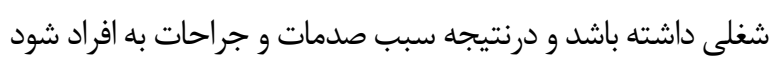

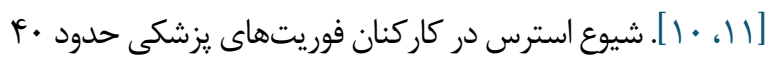

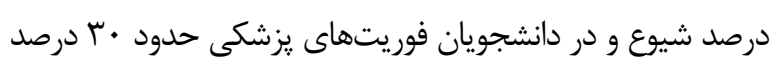

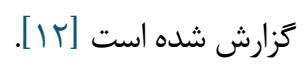
علاوهبر بار استرس كه مىتواند سبب آسيبهاى جسمى

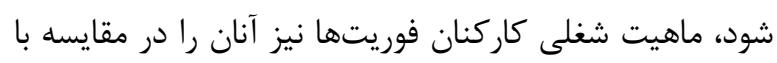

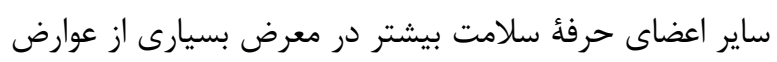

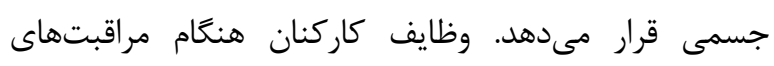
اورزانسى با حداكثر سرعت مانند جابهجايى، بلندكردن، هل داد هادن

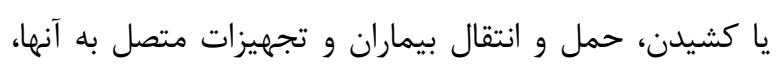

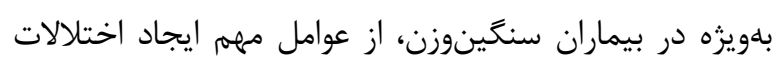

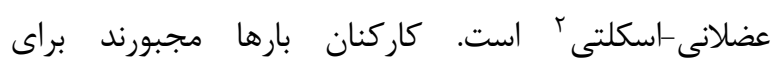

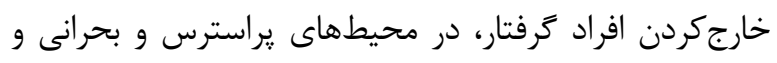

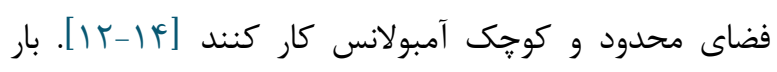

${ }^{2}$. Musculoskeletal disorders

$$
\text { مجله مراقبت يرستارى و مامايى ابنسينا }
$$


نورديك تعديل و تدوين شد. اين يرسشنامه ر I Korinka I همكاران در سال 1911 در انستيتوى بهداشت حرفهاى تلدين كشورهاى حوزه اسكانديناوى طراحى و ارائه كردند كه براى تعيين ميزان شيوع اختلالات اسكلتى- عضلانى در اندامهاى

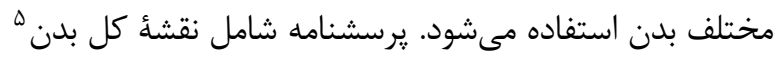

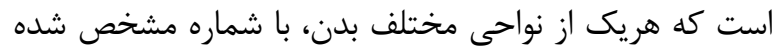

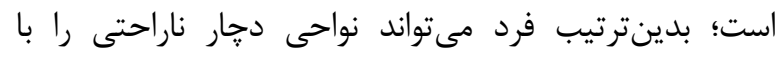

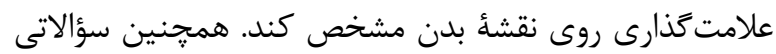

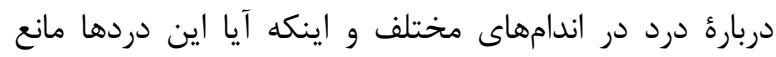

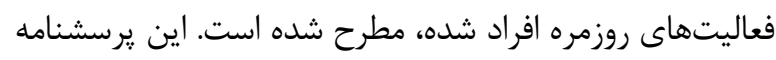

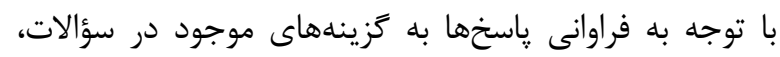

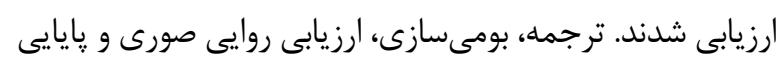

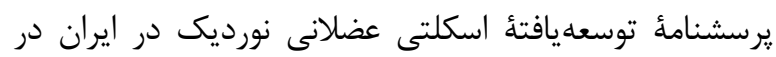

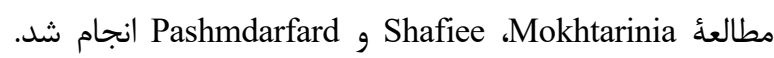
فرايند ترجمه و بومىسازى يرسشنامئ توسعهيافتأ نورديك نيز آسان و مطلوب كزارش شد. نتايج بررسى روايى صورى نرى نشان

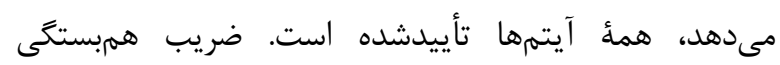

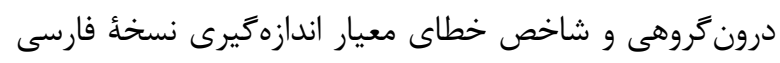

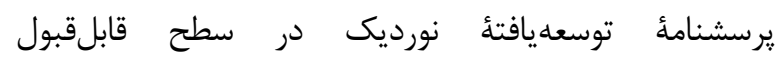
76/1-56/0=SEM ،ICC ، $^{6}>$ •/V•)

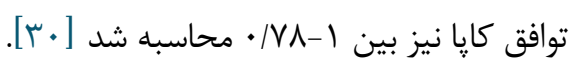

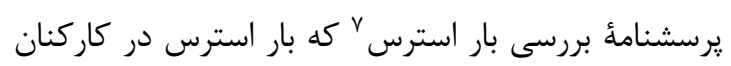

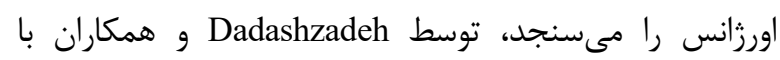

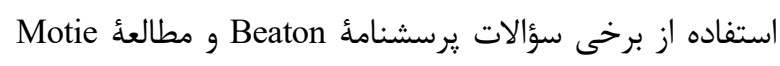

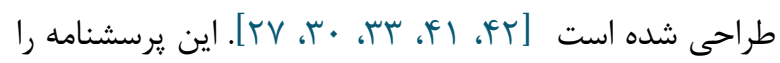
Beaton

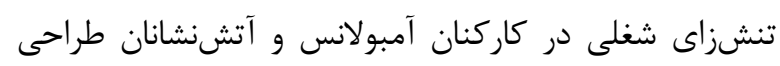

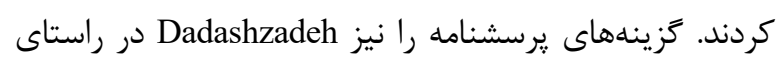

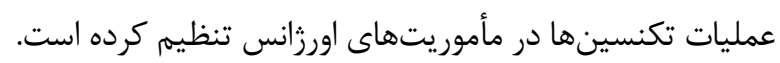

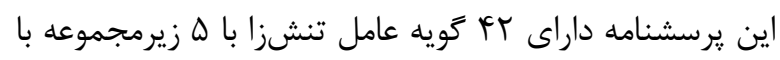

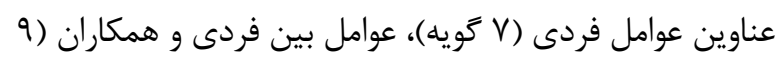

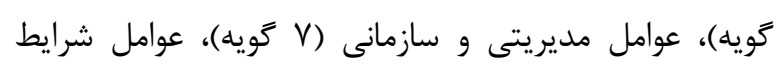

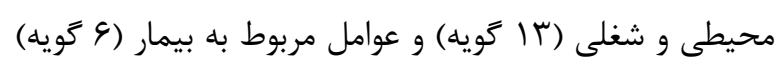

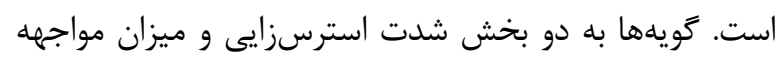

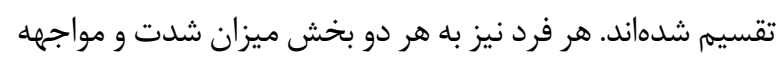

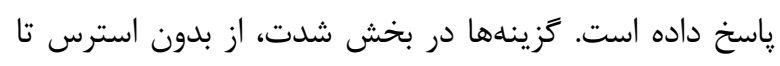

${ }^{6}$. Intraclass Correlations

7. Burden of Stress

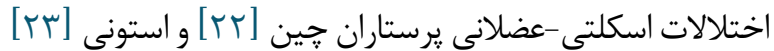

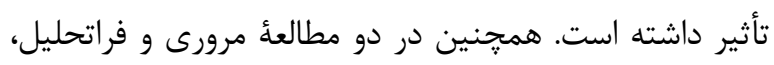

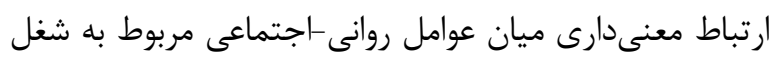

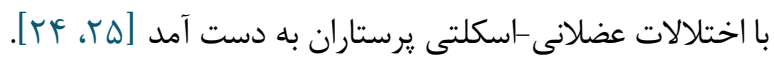

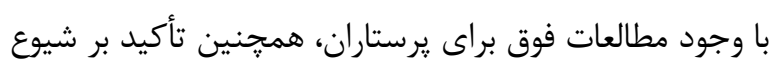

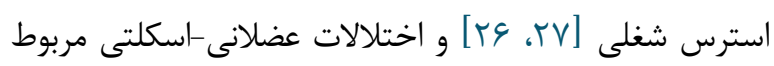

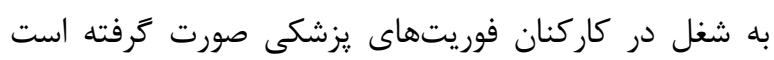

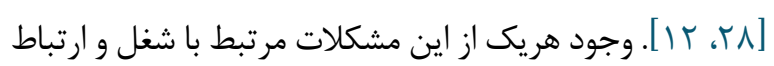

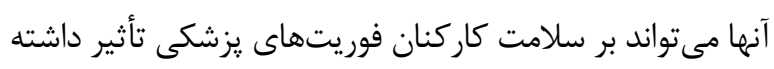

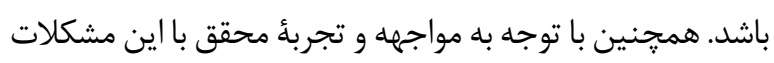

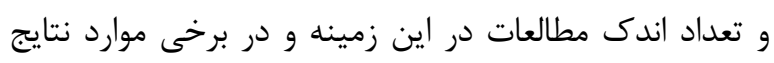

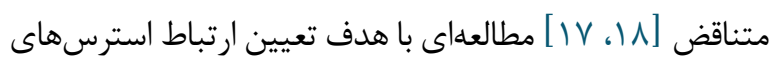
شغلى با اختلالات اسكلتى عضلانى در كاركنان فوريتهاى

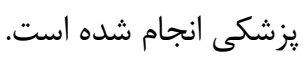

\section{روش كار}

مطالعه توصيفى - همبستخى حاضر در سال

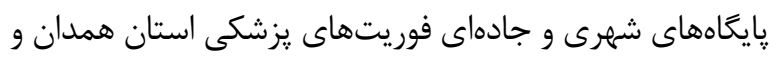

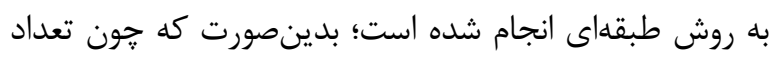

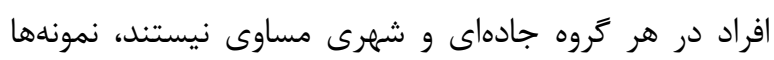

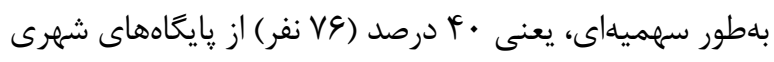

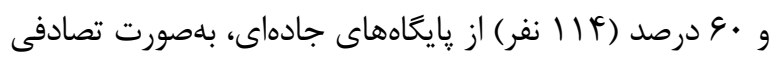

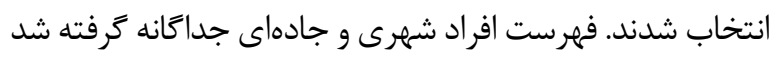
و اين افراد با اعداد تصادفى حاصل از نرمافزار Numbers Generator

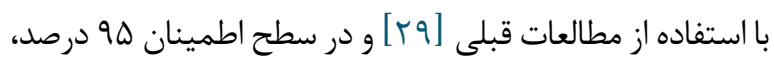

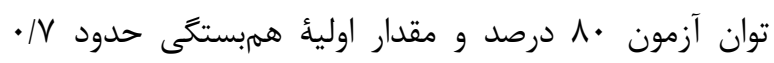

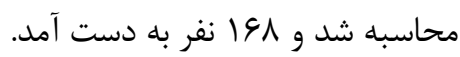
معيارهاى ورود به مطالعه شامل داشتن سابقـ كارى حداقل

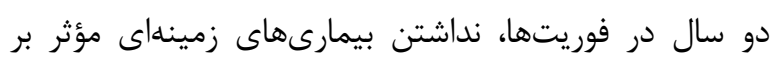

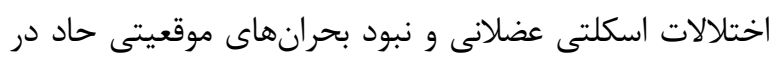

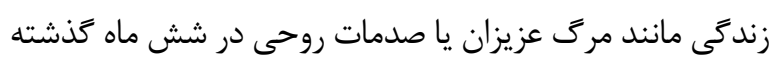

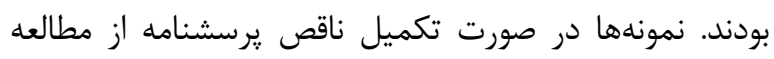

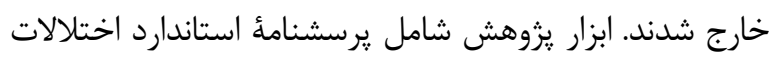

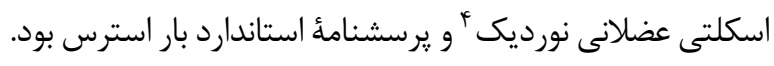

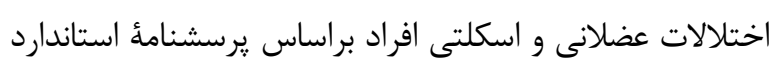

2. Nordic musculoskeletal disorders standard questionnaire 5 . Body map 
يرسشنامةٔ بررسى بار استرس و پِ از آن يرسشنامهٔ مربوط به شيوع اختلالات اسكلتى عضلانى نورديك را تكميل كردند.

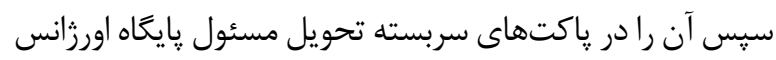

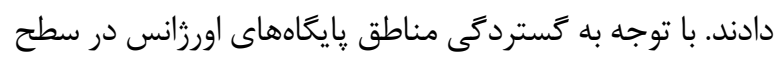
استان و مناطق دوردست و شرايط كارى كاركنان اورزانس پيش بيمارستانى، رساندن يرسشنامهها براى افراد واجد شرايط و

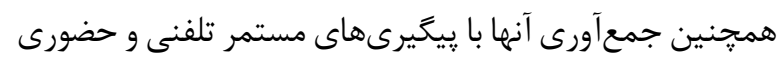

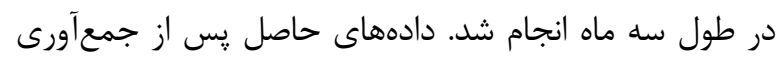

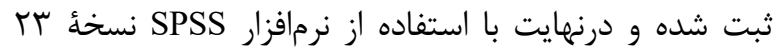

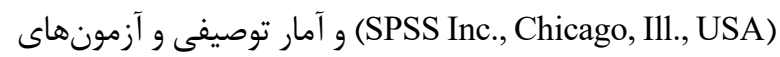
آمارى t مستقل، آناليز واريانس يكىطرفه، ضريب همبستخى ونى اسِيرمن و تحليل رگرسيونى تجزيه و تحليل شد.

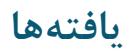

ميانكين (\$انحراف استاندارد) سن كاركنان يزوهش

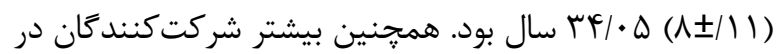

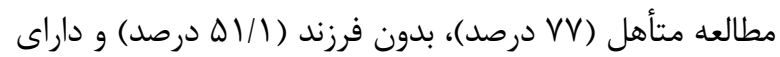

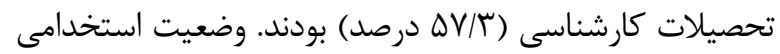

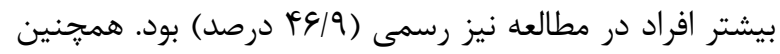

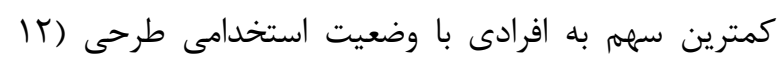
درصد) مربوط بود (جدول إو r).
استرس خيلى زياد و در بخش ميزان مواجهه، از بدون مواجهه

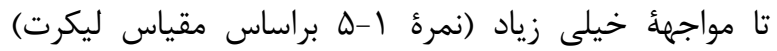
مشخص شدند. براساس يرسشنامه، نمرئ هر فرد از هركدام از عوامل استرسزا (شدت و ميزان مواجهه (-ه) و ميانگين بار استرس (حاصلضرب شدت در ميزان مواجهه) از إ- إس است.

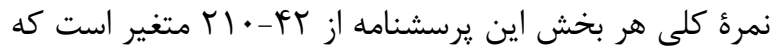

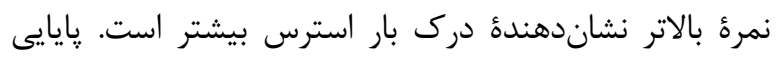

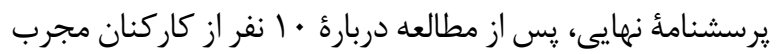

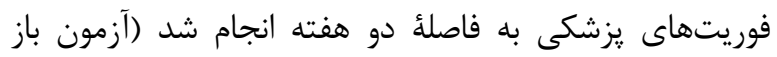

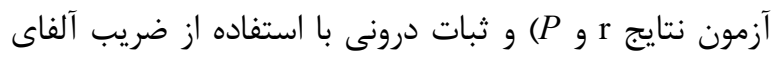

$$
\text { كرونباخ هله • تعيين شد. }
$$

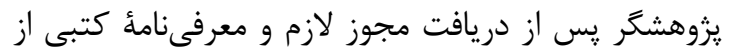

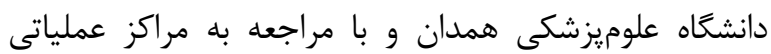

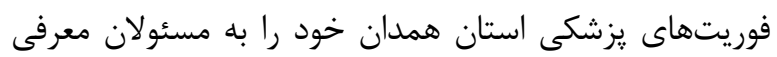
كرد. با ارائه توضيحات لازم و كافى دربارئ يزوهش و و توجيه مسئولان محترم مراكز مورد مطالعه، يرسشنامها دانها در ميان

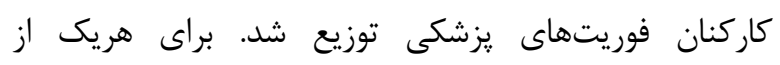

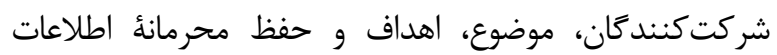

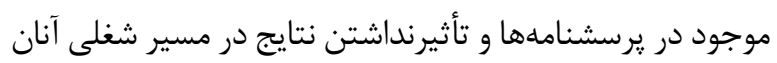

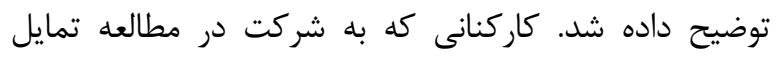

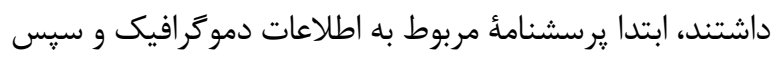

جدول ا. جحكونكَى توزيع متغيرهاى دموَّرافيك كمى واحدهاى مورد يزوهش

\begin{tabular}{|c|c|c|c|c|c|}
\hline انحراف معيار & ميانًَين & 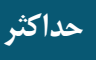 & 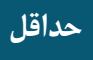 & تعداد & متغير \\
\hline$N / 1$ & $\mu F / \cdot \Delta$ & 9. & r. & ive & سن (سال) \\
\hline $8 / .1$ & $18 \cdot / 99$ & 190 & 19. & iva & قد (سانتيمتر) \\
\hline $1.1 \% q$ & VN/99 & 1.0 & $\Delta \wedge$ & IWr & وزن (كيلوَّرم) \\
\hline$\Delta F / t r$ & $1 \mathrm{KT} / \mathrm{Kr}$ & שאוץ & ז & iva & سابقهُ كار (ماه) \\
\hline Ig/Ar & IVD/ $/ T$ & rA. & $\pi$ & $|v|$ & تعداد ساعت كارى موظفى در ماه \\
\hline $19 / 1 \pi$ & $|f \Psi / T|$ & $\ulcorner\Delta$. & . & 194 & تعداد ساعت اضافهكارى در ماه \\
\hline$r \cdot / r F$ & $\mid \Delta / \Delta \varphi$ & ᄉ. & 1 & il & 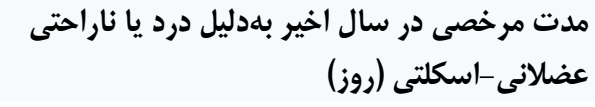 \\
\hline$r 9 / 19$ & $T r / T \Delta$ & ir. & 1 & צ' & مرختى بهد (ماه) \\
\hline
\end{tabular}


جدول ا. توزيع فراوانى مطلق و نسبى واحدهاى مورد يخوهش از نظر متغيرهاى دموكرافيك

\begin{tabular}{|c|c|c|c|}
\hline درود & تعداد & سطوح متغير & متغير \\
\hline r & (i) & مجرد & \multirow{2}{*}{ وضعيت تأهل } \\
\hline V V & Irv & متأهل & \\
\hline$\Delta 1 / 1$ & v. & . & \multirow{4}{*}{ تعداد فرزند } \\
\hline$r q / r$ & r. & 1 & \\
\hline $\mid f / 9$ & $r$. & $r$ & \\
\hline$\Delta / 1$ & v & r & \\
\hline Tr/S & $\Delta \Lambda$ & كاردانى & \multirow{3}{*}{ ميزان تحصيلات } \\
\hline$\Delta V / T$ & $1 . r$ & كارشناسى & \\
\hline $1 . / r$ & 11 & كارشناسى ارشد و بالاتر & \\
\hline IT & rI & طرحى & \multirow{4}{*}{ وضعيت استخدام } \\
\hline$\uparrow \& / 9$ & NT & رسمى & \\
\hline$r \Lambda$ & $1 q$ & ييمانى & \\
\hline $1 m / 1$ & r & قراردادى & \\
\hline 9 & 10 & بلى بلى & \multirow{2}{*}{ مصرف سيگًار } \\
\hline 91 & r & 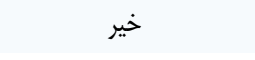 & \\
\hline $18 / 9$ & $r$. & بلى - منظم & \multirow{3}{*}{ انجام ورزش } \\
\hline SV/T & 119 & بلى - نامنظم & \\
\hline $10 / \Lambda$ & $r \Lambda$ & خير & \\
\hline$V \& / \Delta$ & 91 & هوازى & \multirow{2}{*}{ نوع ورزش } \\
\hline$r M / D$ & ru & بـ موازى & \\
\hline
\end{tabular}

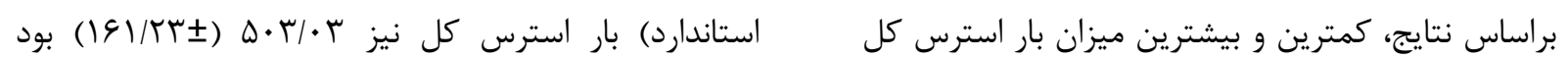

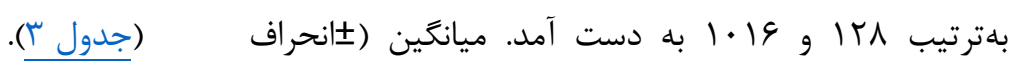

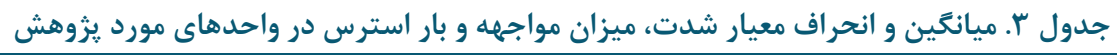

\begin{tabular}{|c|c|c|c|}
\hline بار استرس & ميزان مواجهه & شدت مواجهه & \multirow{2}{*}{ بعد } \\
\hline \multicolumn{3}{|c|}{ انحراف معيار 土 ميانگين } & \\
\hline$V \Delta / / \Lambda \pm r \wedge / / Q$ & $r / / \cdot r \pm \Delta / \cdot 1$ & $r r / \cdot \Lambda \pm F / V r$ & عوامل فردى \\
\hline$q \cdot / \uparrow \wedge \pm r V / r r$ & $r \varepsilon / 99 \pm \varepsilon / r \Delta$ & $r V / \varphi q \pm q / r \Delta$ & عوامل بينفردى و همكاران \\
\hline$V \Lambda / \cdot V \pm r M / \Lambda \Lambda$ & $r T / T \Delta \pm \Delta / r \Delta$ & $r T / G T \pm \Delta / 9 \Delta$ & عوامل مديريتى و يشتيبانى \\
\hline $\mid \Lambda V / F F \pm \Delta \Lambda / F \Delta$ & $F \Delta / G \psi \pm \Lambda / \Delta$ & $\Delta) / \Delta V \pm \wedge / \wedge \varphi$ & عوامل شرايط محيطى و شغلى \\
\hline$V \Psi / T \cdot \pm r \Delta / \wedge \varphi$ & $|N / F V \pm F / T|$ & 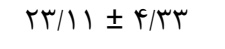 & عوامل مربوط به بيمار \\
\hline$\Delta \cdot r / \cdot r \pm \mid \varepsilon 1 / r r$ & $I r r / V T \pm r \Delta / r q$ & $\mid f \wedge / \cdot \Lambda \pm r \Delta / F r$ & كل \\
\hline
\end{tabular}


بيشترين ميزان بار استرس بهترتيب در كاركنان با وضعيت

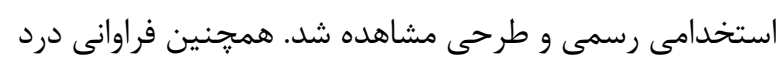

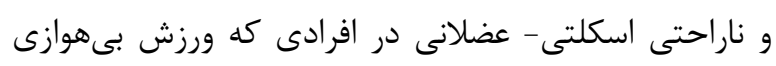

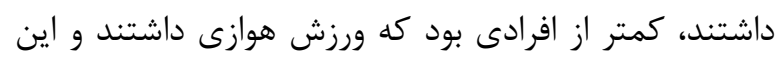

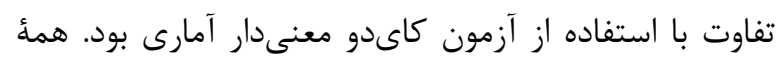

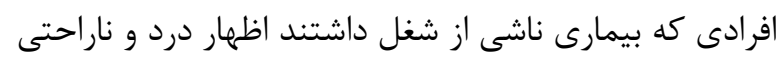

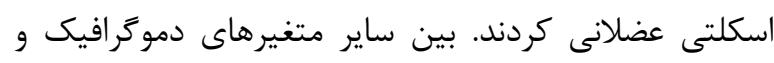

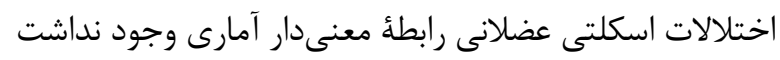

(جدول (خنالت).
ميانگين سابقه كارى و مدت اشتغال افرادى كه اظهار درد

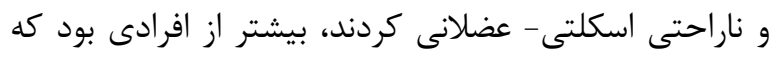

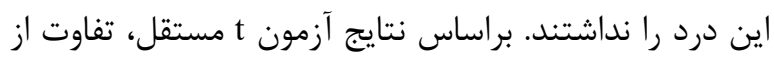

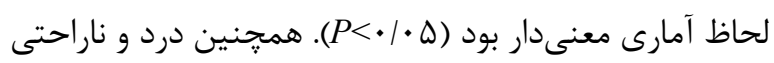

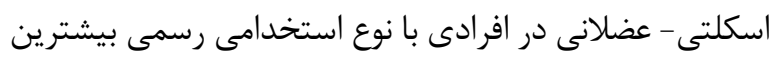

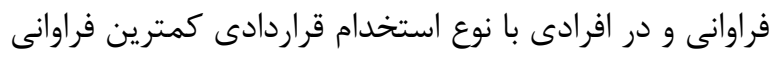

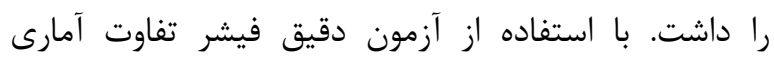

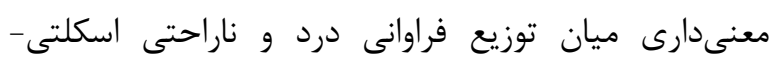
عضلانى افراد با نوع استخدام متفاوت وجود داشت. كمترين و وراني

جدول ؟. مقايسهُ ميانكَين متغيرهاى دموكر افيك كمى بين افرادى كه درد و ناراحتى اسكلتى عضلانى داشتند و افرادى كه درد و ناراحتى اسكلتى عضلانى نداشتند

\begin{tabular}{|c|c|c|c|c|}
\hline \multirow{2}{*}{ P-value } & \multirow{2}{*}{ آمارة آزمون t مستقل } & \multicolumn{2}{|c|}{ درد و ناراحتى اسكلتى -عضلانى } & \multirow{2}{*}{ متغير } \\
\hline & & 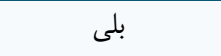 & خير & \\
\hline .1 .99 & $t=-1 / \wedge \mu$ & $r \digamma / r q \pm \varepsilon / 1 \Delta$ & $r \cdot / 4 \cdot \pm \varepsilon / 1 \Delta$ & سن (سال) \\
\hline . LAT & $\mathrm{t}=-\cdot / \mathrm{v}$ & $\mid V V / \Lambda \cdot \pm \Delta / 9 \Delta$ & $|V \&| \& \Lambda \pm \& / 9 q$ & قد (سانتىمتر) \\
\hline$\cdot|\& Y|$ & $\mathrm{t}=\cdot|\wedge|$ & $V N / \notin q \pm 1 . / \leftarrow q$ & $\Lambda \cdot / 89 \pm \wedge / 9 \Lambda$ & وزن (كيلوكَم) \\
\hline .1 .49 & $\mathrm{~g}=-r / r$. & $\mid r \Delta / \& \Delta \pm \wedge F / v \Lambda$ & $\Lambda V / \& V \pm s \Delta / \&$. & سابقه كارى (ماه) \\
\hline.$/ .4 q$ & $\mathrm{t}=-r / r$. & $|T V / \mathscr{F} \Lambda \pm \Lambda| / \cdot \Delta$ & $\Lambda r / \Delta V \pm \Delta N / \cdot r$ & مدت اشتغال (ماه) \\
\hline$\cdot / 1 \Delta Q 9$ & $\mathrm{t}=\cdot / \mathrm{M}$ & $\mid V \Delta / r \Delta \pm I V / \Delta S$ & $\mid v \varepsilon / \cdot V \pm r / l r$ & تعداد ساعت كارى موظفى \\
\hline.$/ 94 \Lambda$ & $\mathrm{t}=-. / 4 \varepsilon$ & $\mid f F / W V \pm F N / q \Lambda$ & $\mid r V / G V \pm \Delta F / \mathcal{L}$ & تعداد ساعت اضافهكار \\
\hline . MIT & $\mathrm{t}=-\cdot / r \mathrm{r}$ & $r / r q \pm q / q q$ & $I / H T \pm \cdot / A V$ & مدت ورزش (ساعت) \\
\hline
\end{tabular}

بود. ميزان بار استرس در كاركنانى كه براساس اظهارات

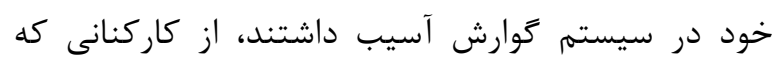

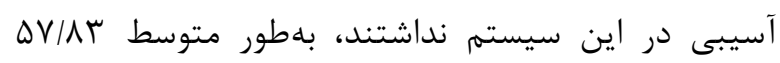

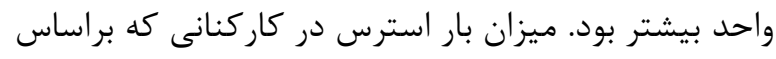

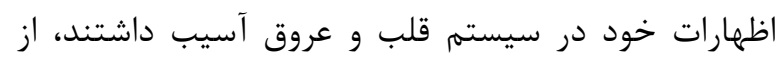

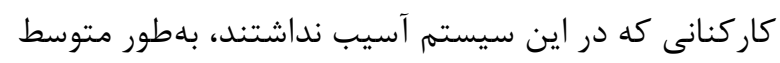

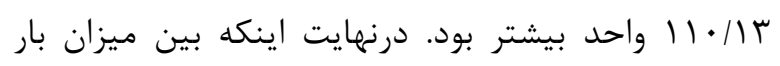

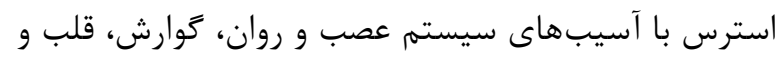
عروق، سيستم دفعى و يوست و مو رابطهُ معنى دار آسئه آمارى وجود داشت (جدول ه).
براساس نتايج، ميزان بار استرس در كاركنانى كه اعلام

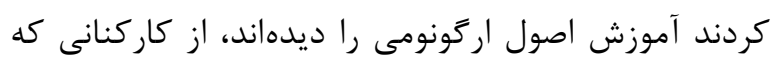

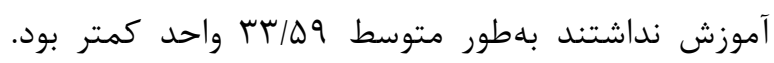

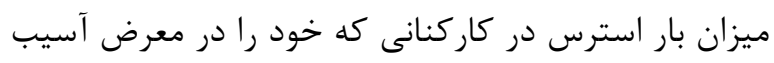

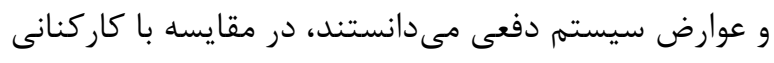

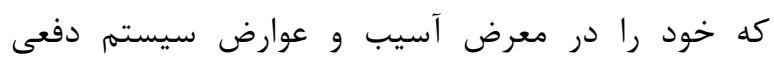

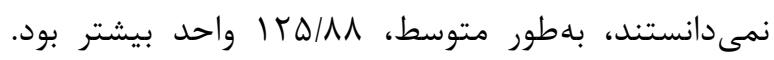

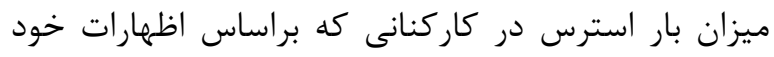

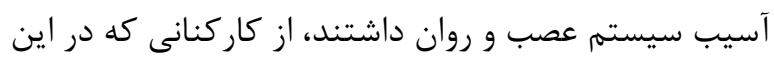

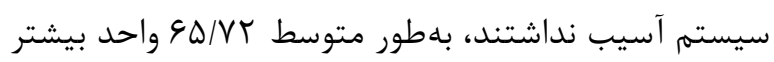


جدول ه. مقايسهُ ميزان بار استرس در واحدهاى مورد يثوهش با وضعيت مختلف از نظر آسيب سيستم بدن آنها

\begin{tabular}{|c|c|c|c|c|}
\hline نتيجهُ آزمون & انحراف استاندارد د ميانكَين & ت تعداد & سطوح متغير & متغير \\
\hline $\mathrm{t}=-\cdot / \lambda \mathrm{F}$ & $F N \& / \Delta V \pm|Q| / \Delta Q$ & 19 & خير & \multirow{2}{*}{ آسيب سيسته عضلانى - اسكلتى } \\
\hline$P=\cdot / \kappa \cdot r$ & $0.9 / K F \pm 1 G F / \Lambda \varepsilon$ & m. & بلى بلى & \\
\hline$t=-r / V^{F}$ & $\lceil 99 / \cdot 1 \pm 1 \uparrow N / \wedge \Delta$ & 111 & خير & \multirow{2}{*}{ آسيب سيستم عصب و روان } \\
\hline$P<\cdot / . \cdot 1$ & $\Delta \Delta N / \Delta V \pm 198 / R \&$ & $9 \Lambda$ & بله & \\
\hline$t=-r / r r$ & $F V / \wedge r \pm 1 \varepsilon \cdot / 1 D$ & 110 & خير & \multirow{2}{*}{ آسيب سيستم كَوارش } \\
\hline$P=. / \cdot r$ & $\Delta \Delta T / V \cdot \pm|\Delta| / \Delta V$ & se & 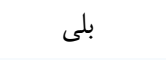 & \\
\hline $\mathrm{t}=-r / \Delta S$ & $\uparrow \wedge q / / r \pm \mid \omega r / r \Lambda$ & $|9|$ & خير & \multirow{2}{*}{ آسيب سيستم قلب و عروق } \\
\hline$P<\cdot / . .1$ & s rV/rq $\pm|\Lambda| / r \Delta$ & $M$ & 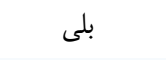 & \\
\hline $\mathrm{t}=-2 / \mathrm{Fr}^{\mathrm{c}}$ & $|\vee q Y / \Delta q \pm| \Delta \& / \cdot \Lambda$ & $19 \Delta$ & خير & \multirow{2}{*}{ آسيب سيستم دفعى } \\
\hline$P=. / .19$ & $G \cdot r / \Delta \cdot \pm|9 r / \Delta|$ & 11 & 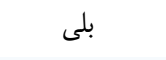 & \\
\hline $\mathrm{t}=-r / \cdot \cdot$ & rqT/rq \pm |qT/Fr & 1199 & خير & \multirow{2}{*}{ آسيب سيستم يوست و مو } \\
\hline$P=. / .+\mathrm{VV}$ & $\Delta \Delta \varepsilon / r V \pm \mid r \varepsilon / r q$ & $r$. & بله & \\
\hline$t=-. / 99$ & $\Delta \cdots / f^{+} \pm|\varepsilon| / 1 \mid$ & $|V|$ & خير & \multirow{2}{*}{ آسيب سيستم جنسى } \\
\hline$P=\cdot / T T_{1}$ & $\Delta \Delta \Lambda / \Delta \cdot \pm \mid \xi \kappa / F \Lambda$ & $\wedge$ & بله & \\
\hline
\end{tabular}

كه اظهار درد يا ناراحتى در ناحيةُ گردن داشتند، بهطور متوسط ميزان بار استرس بيشترى از ساير كاركنانى داشتند

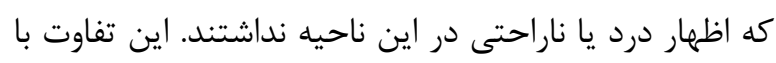

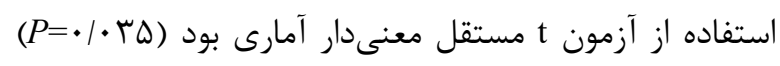

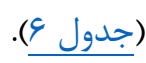

در ادامهُ نتايج، كاركنانى كه اعلام كردند بهدليل شغل درد يا ناراحتى عضلانى-اسكلتى دارند، بهطور متوسط ميزان بار

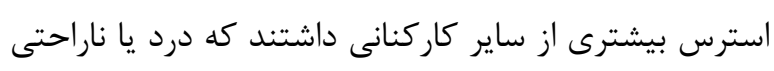
عضلانى -اسكلتى بهدليل شغل نداشتند. اين تفاوت با استفاده از آزمون t مستقل معنى دار آمارى نبود (

جدول צ. مقايسُٔ ميزان بار استرس در واحدهاى مورد يزوهش با وضعيت مختلف از نظر وجود درد و ناراحتى اسكلتى -عضلانى

\begin{tabular}{|c|c|c|c|c|}
\hline \multicolumn{2}{|c|}{ 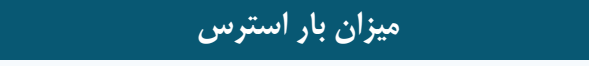 } & \multirow{2}{*}{ تعداد } & \multirow{2}{*}{ سطغوح } & \multirow{2}{*}{ متغير } \\
\hline نتيجة آزمون & انحراف استاندارد 土 ميانكين & & & \\
\hline $\mathrm{t}=\cdot / \mathrm{HF}^{\mathrm{c}}$ & $Q \cdot F / T r \pm I G T / F V$ & سعا & 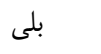 & \multirow{2}{*}{ درد يا نار احتى عضلانى -اسكلتى بهدليل شغل } \\
\hline$P=/ /$ T $ه$ & $r \wedge Q / Q \uparrow \pm I \Delta T / \mu F$ & 19 & خير & \\
\hline $\mathrm{t}=-r / I r$ & $\Delta G Y / \Lambda \mid \pm 1 G \cdot / R T$ & tr & بلى بلى & \multirow{2}{*}{ درد يا ناراحتى در ناحية َّردن } \\
\hline$P=. / . r \omega$ & (q)/Vq \pm ।Qq/AV & $\mid 01$ & خير & \\
\hline $\mathrm{t}=-1 / \Delta \mathrm{g}$ & $\Delta \Gamma I / T \Delta \pm \mid \& r / K F$ & $\Delta F$ & 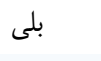 & \multirow{2}{*}{ درد يا ناراحتى در ناحية دستها } \\
\hline$P=. / \mathrm{ht}$ & $19 q . / .9 \pm 191 / 91$ & $|r|$ & 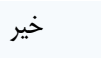 & \\
\hline $\mathrm{t}=-\cdot / 9 \mathrm{~V}$ & $\Delta|F / \xi \pi \pm| \& \varepsilon / \uparrow \Lambda$ & 90 & 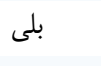 & \multirow{2}{*}{ درد يا ناراحتى در ناحيئ پاها } \\
\hline$P=. / \mu r \mu$ & $p q . / q) \pm \mid V V / q q$ & 11 & 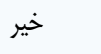 & \\
\hline $\mathrm{t}=-\cdot / \mu \omega$ & $D \cdot F / 9 \Lambda \pm \mid \& T / K \varepsilon$ & IfT & 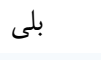 & \multirow{2}{*}{ درد يا ناراحتى در ناحية ستون فقرات } \\
\hline$P=\cdot / V^{\mu}$. & $R q F / R T \pm \mid \Delta \& / \& T$ & 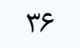 & خير & \\
\hline
\end{tabular}


در ادامٔ نتايج اين مطالعه، همء كاركنانى كه بهدليل شغل با

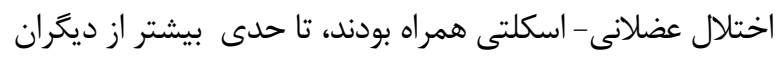

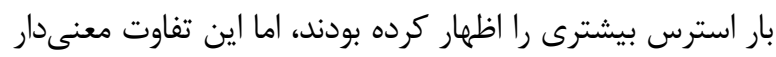

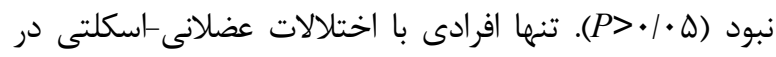

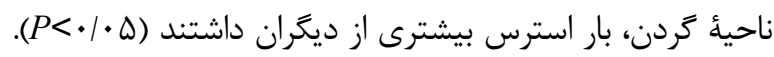

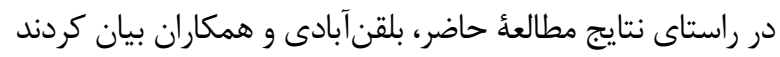
كه بين استرس و اختلالات اسكلتى-عضلانى در اندام تحتانى

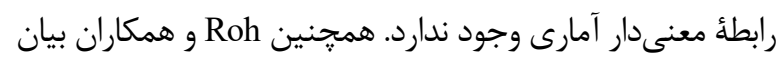

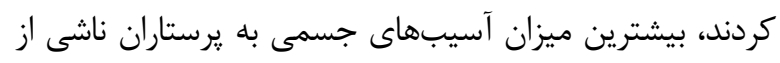

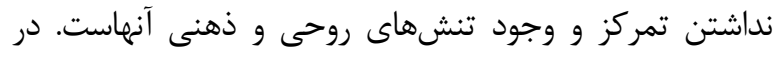

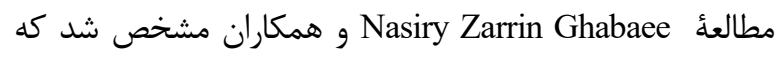
بين دو بعد استرس شغلى (تقاضا و حمايت همكاران) با اختلالات

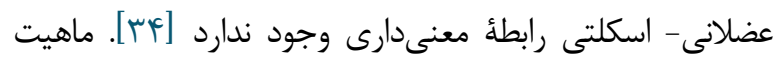

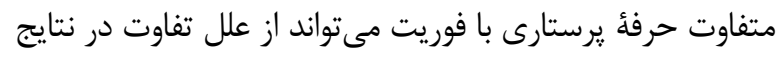
باشد. همجنين از ابزارهاى متفاوتى در دو مطالعه استفاده شده

نتايج مطالعه حاضر در زمينهُ رابطهٔ سابقهُ كار با اختلالات

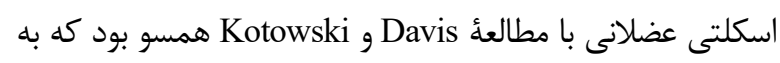

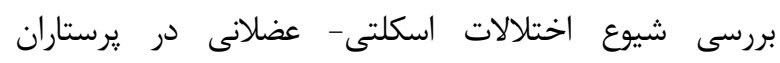

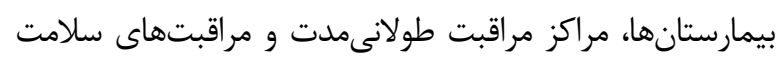

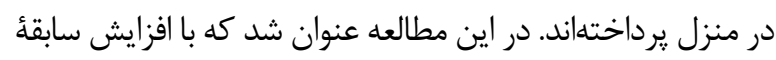
كارى، احتمال اختلالات اسكلتى- عضلانى افزايش يافته است.

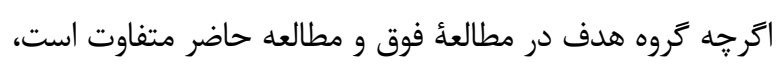

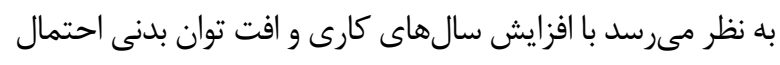

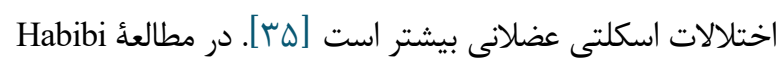

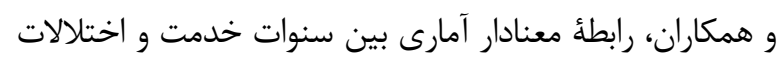
اسكلتى - عضلانى در يرستاران وجود داشت [عبان معادئ.

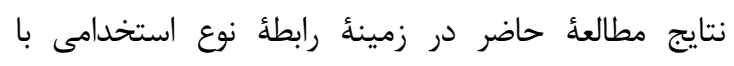

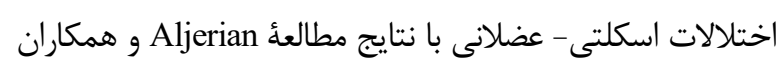

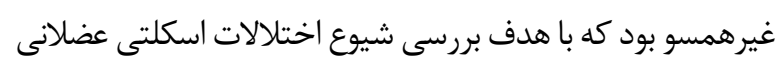

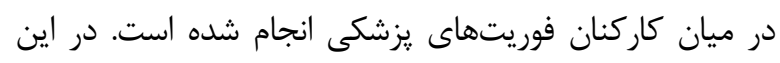

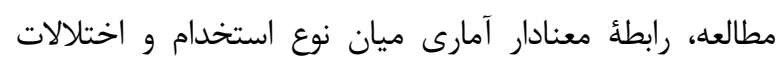

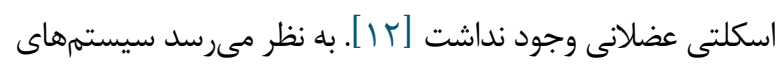
متفاوت خدمات سلامت دو كشور (تفاوتهاى نوع استخدام و...)

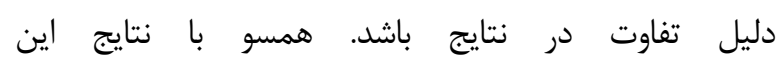
مطالعه، Dadashzadeh و همكاران بيان كردند كه بين نوع بايج
مطالعه حاضر با هدف تعيين همبستخى اختلالات اسكلتى - بحت

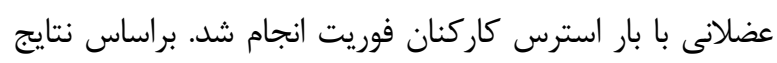

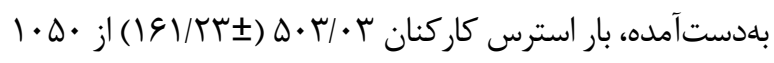

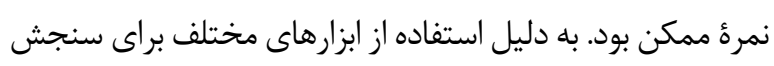
استرس شغلى كاركنان تيم يزشكى از جمله كاركنان فوريت،

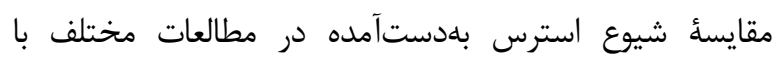
محدوديت روباروست. در نتايج بهدست آمده بيشترين ميانكَين

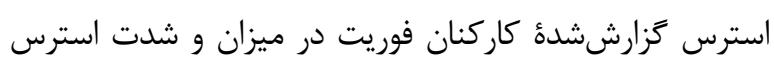

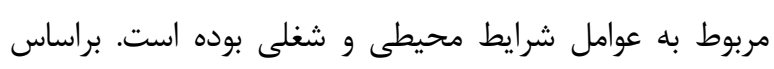

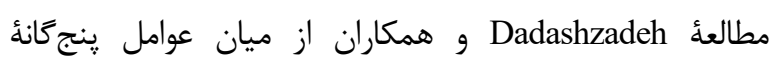

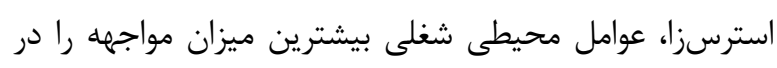

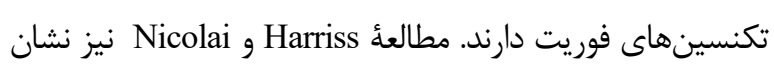

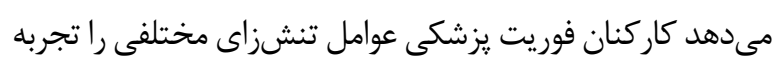

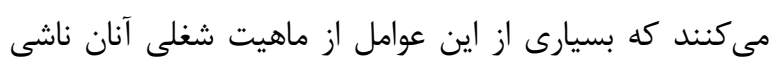

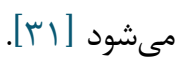

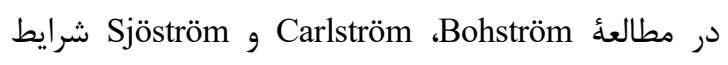

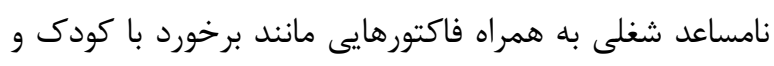

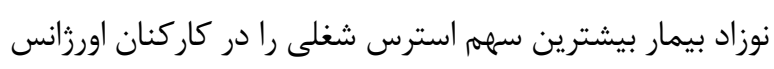

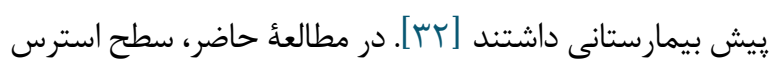
شغلى كاركنان در سطح نمرءٔ ميانكَين متوسط بوده است. نتائج

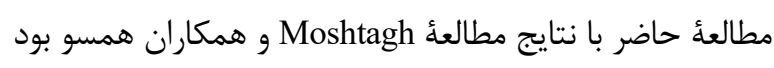

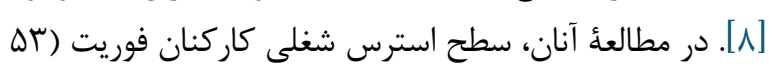

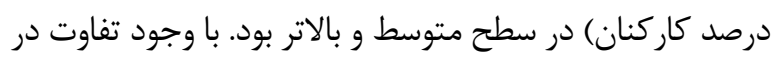

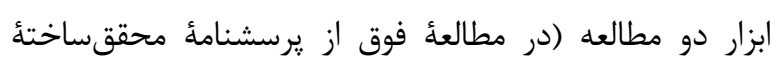

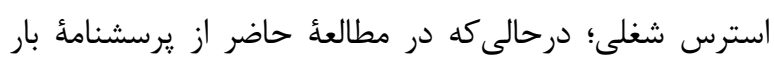

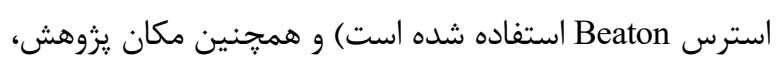

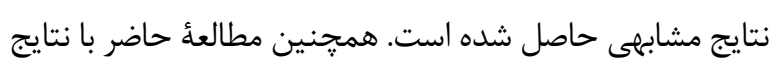

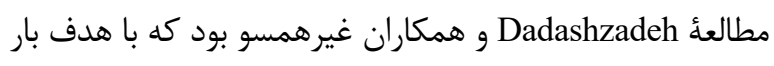

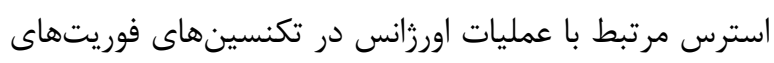

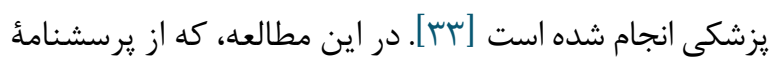

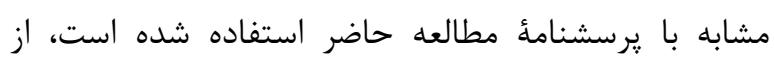
مجموع FFV مورد بررسىشده ميانكين شدت و و ميزان

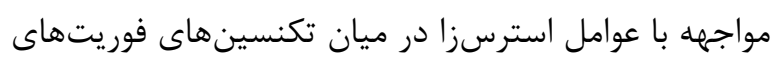

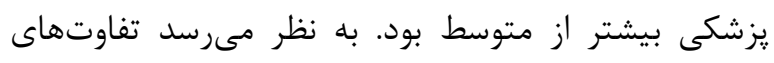

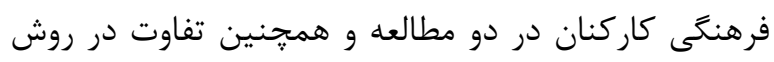
كار دليل تفاوت در نتايج باشد. 
استرس مىتوان كام مهمى در كاهش اختلالات جسمى

$$
\text { كاركنان فوريت برداشت. }
$$

$$
\text { سياسگز ارى }
$$

اين مقاله برگرفته از ياياننامd دوره كارشناسى ارشد

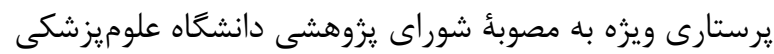
و خدمات بهداشتى درمانى همدان است. همجنين اين طرح

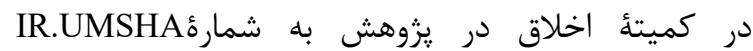

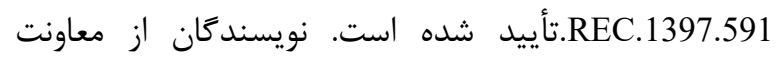
محترم تحقيقات و فناورى دانشعاه و اعضاى محترم هيئت علمى دانشكدة يرستارى و مامايى، همأ مسئولان محترم مراكز فوريتهاى يزشكى استان همدان و نيز همهٔ كاركنان فوريتهاى يزشكى شركت كننده در اين مطالعه، تشكر و و قدردانى مى كنند.

$$
\text { تعارض در منافع }
$$

بين نويسندكان هيجگَّه تعارضى در منافع وجود ندارد

$$
\text { منابع مالى }
$$

منابع مالى اين مطالعه توسط نويسندگًان تامين شده است.

\section{References}

1. Rajabi F, Jahangiri M, Molaeifar H, Honarbakhsh M, Farhadi P. Occupational stress among nurses and prehospital emergency staff: application of fuzzy analytic hierarchy process (FAHP) method. EXCLI J. 2018;17:808. (In Persian)

2. Boland LL, Kinzy TG, Myers RN, Fernstrom KM, Kamrud JW, Mink PJ, Stevens AC. Burnout and exposure to critical incidents in a cohort of emergency medical services workers from Minnesota. West J Emerg. 2018;19(6):987. [DOI:10.5811/westjem.8.39034] [PMID] [PMCID]

3. Shareinia H, Khalilian R, Bloochi Beydokhti T, Javadi $\mathrm{H}$. Relationship between job satisfaction and burnout among prehospital emergency staff. Q J Nurs Manag. 2017;6(2):9-19. [DOI:10.29252/ijnv.6.2.9]

4. Lu Y, Hu XM, Huang XL, Zhuang XD, Guo P, Feng LF, Hu W, Chen L, Hao YT. Job satisfaction and associated factors among healthcare staff: a crosssectional study in Guangdong Province, China. BMJ Open. $2016 \quad$ Jul 1;6(7):e011388. [DOI:10.1136/bmjopen-2016-011388] [PMID] [PMCID]
استخدامى و اختلالات اسكلتى- عضلانى در تكنسينهاى فوريت يزشكى ارتباط معنى دار آمارى وجود ندارد. براساس نتايج مطالعه Nasiry Zarrin Ghabaee و همكاران، ميان نوع استخدامى و سنوات خدمت با اختلالات اسكلتى - عضلانى مئى رابطة معنى ارار آمارى وجود دارد؛ درحالى كه ميان ساير متغيرها از جمله نوع ورزش هوازى و بىهوازى رابطهُ معنى مدار آمارى وجود ندارد [rv]. يزوهش حاضر از لحاظ حوزه مطالعات مرتبط با استرس و و مأودود اختلالات شغلى در حيطة كاركنان فوريت، مزاياى قابلتوجهى دارد. حجم نمونه مناسب و استفاده از يرسشنامههاى استاندارد از جمله نقاط قوت مطالعه است. ريشنههاد مىشود مطالعات مشابه با حجم نمونه بالاتر انجام شود.

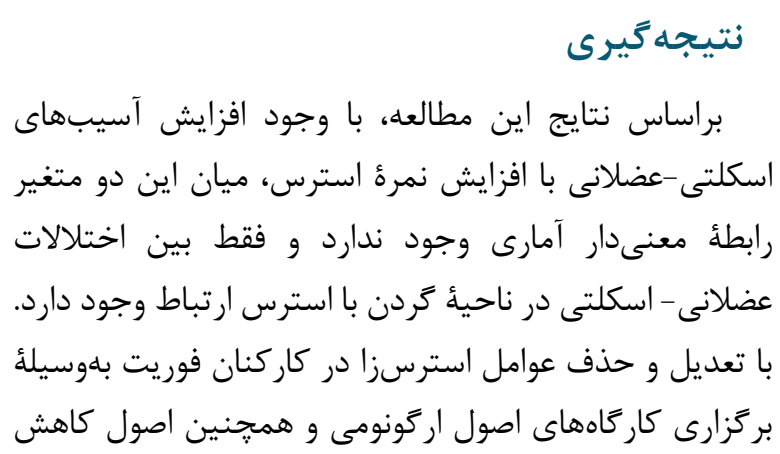

5. Javaeed A, Malik MN, Yaseen M, Abbasi TJSAJoEM. Emergency Medical Services and Quality of Care in Emergency Departments: Knowledge, Attitude and Practices among General Population in Rawalpindi, Pakistan. South Asian J Emerg Med. 2018;1(1):22-8. (In Persian) [DOI:10.5455/sajem.184-1533501091]

6. Askari R, Bahrami MA, Pahlavanpoor SR, Afzali F. Development of performance evaluation indicators for pre-hospital emergency centers. Bali Med J. 2018;7(1):182-91. [DOI:10.15562/bmj.v7i1.898]

7. Tarcan M, Hikmet N, Schooley B, Top M, Tarcan GY. An analysis of the relationship between burnout, socio-demographic and workplace factors and job satisfaction among emergency department health professionals. Appl Nurs Res. 2017;34:40-7. [DOI:10.1016/j.apnr.2017.02.011] [PMID]

8. Moshtagh Eshgh Z, Aghaeinejad AA, Peyman A, Amirkhani A, Chehregosha M. Relationship between occupational stress and mental health in male personnel of medical emergency in Golestan Province. J Res Dev Nurs Midw. 2015;12(1):29-38. 
9. Mahboubi M, Jalali A, Mohammadi MJHJ Comparative assessment of relationship between sensation seeking with job stress in emergency medicine workers and non emergency medicine workers. Hosp J. 2013;12(3).

10. Bernaldo-De-Quirós M, Piccini AT, Gómez MM, Cerdeira JC. Psychological consequences of aggression in pre-hospital emergency care: cross sectional survey. Int J Nurs Stud. 2015;52(1):260-70. [DOI:10.1016/j.ijnurstu.2014.05.011] [PMID]

11. Maryam H, Arbabisarjou A, Aziz S, Dariush R. Identification of occupational stress factors in male medical technicians rendering pre-hospital emergency care at Zabol University of medical sciences. International J Pharm Tech. 2016;8(2):12400-9. (In Persian)

12. Aljerian N, Alshehri S, Masudi E, Albawardi AM, Alzahrani F, Alanazi R. The Prevalence of Musculoskeletal Disorders among EMS Personnel in Saudi Arabia, Riyadh. Egypt J Hosp Med. 2018 ;73(1):5777-82

13. Fisher TF, Wintermeyer SF. Musculoskeletal disorders in EMS: Creating employee awareness. Prof Safety. 2012 Jul 1;57(07):30-4.

14. Adib-Hajbaghery M, Zohrehea J. Back pain among paramedics: a pilot study. Nurs Midwifery Stud. 2013;2(4):e12195. (In Persian) [DOI:10.5812/nms.12195] [PMID] [PMCID]

15. Yoon J, Yi K, Kim S, Oh J, Lee J. The relationship between occupational stress and musculoskeletal symptoms in call center employees. Korean J Occup Environ Med. 2007;19(4):293-303. [DOI:10.35371/kjoem.2007.19.4.293]

16. Bonzini M, Veronesi G, Conti M, Coggon D, Ferrario MM. Is musculoskeletal pain a consequence or a cause of occupational stress? A longitudinal study. Int Arch Occup Environ Health. 2015;88(5):607-12. [DOI:10.1007/s00420-014-0982-1] [PMID] [PMCID]

17. Barzideh M, Choobineh AR, Tabatabaee HR. Job stress dimensions and their relationship to musculoskeletal disorders in Iranian nurses. Work. 2014;47(4):423-9. [DOI:10.3233/WOR-121585] [PMID]

18. Habibi E, Taheri MR, Hasanzadeh A. Relationship between mental workload and musculoskeletal disorders among Alzahra Hospital nurses. Iran J Nurs Midwifery Res. 2015;20(1):1

19. Mutanda T, Mwaka E, Sekimpi P, Ntuulo J. Occupation-related musculoskeletal disorders among nurses at the National Referral Hospital, Mulago in Uganda. Occup Med Health Aff. 2017;5(3):1-5. [DOI:10.4172/2329-6879.1000267]

20. Schleifer LM, Ley R, Spalding TW. A hyperventilation theory of job stress and musculoskeletal disorders. Am J Ind Med. 2002;41(5):420-32. [DOI:10.1002/ajim.10061] [PMID]
21. Mehrdad R, Dennerlein JT, Haghighat M, Aminian O. Association between psychosocial factors and musculoskeletal symptoms among Iranian nurses. Am J Ind Med. 2010;53(10):1032-9. [DOI:10.1002/ajim.20869] [PMID]

22. Smith DR, Wei N, Zhang YJ, Wang RS Musculoskeletal complaints and psychosocial risk factors among physicians in mainland China. Int J Indus Ergon. 2006;36(6):599-603. [DOI:10.1016/j.ergon.2006.01.014]

23. Freimann T, Coggon D, Merisalu E, Animägi L, Pääsuke M. Risk factors for musculoskeletal pain amongst nurses in Estonia: a cross-sectional study. BMC Musculoskelet Disord. 2013;14(1):334. [DOI:10.1186/1471-2474-14-334] [PMID] [PMCID]

24. Bernal D, Campos-Serna J, Tobias A, Vargas-Prada S Benavides FG, Serra C. Work-related psychosocial risk factors and musculoskeletal disorders in hospital nurses and nursing aides: a systematic review and meta-analysis. Int J Nurs Stud. 2015;52(2):635-48. [DOI:10.1016/j.ijnurstu.2014.11.003] [PMID]

25. Motamedzade M, Asghari M, Basati M, Safari $H$, Afshari M, Abbassinia M. The relationship between Work Engagement and Job Stress among Emergency Technicians of Markazi Province, Iran, in 2015. Iran J Health Saf Environ. 2019;6(2):1259-66. (In Persian)

26. Iranmanesh S, Tirgari B, Bardsiri HS. Post-traumatic stress disorder among paramedic and hospital emergency personnel in south-east Iran. World J Emerg Med. 2013;4(1):26 [DOI:10.5847/wjem.j.issn.1920-8642.2013.01.005] [PMID] [PMCID]

27. Motie MR, Kalani MR, Samadi A, Eshaghi H, Ghobadi P. Prevalence of job stressorsin male prehospital emergency technicians. Q J Fundam Mental Health. 2010.12(1):420-429

28. Khazaei A, Esmaeili M, Navab E. The Most and Least Stressful Prehospital Emergencies from Emergency Medical Technicians' View Point; a Cross-Sectional Study. Arch Acad Emerg Med. 2019;7(1).

29. Tabatabaei S, Khani Jazani R, Kavousi Dolanghar A, Rostami K, Najafi Z. The relationship between rate and sources of job stress and musculoskeletal pains among the staff of one hospital in Tehran city, Iran. Qom Uni Med Sci J. 2017;11(4):72-9.

30. Mokhtarinia H, Shafiee A, Pashmdarfard M Translation and localization of the Extended Nordic Musculoskeletal Questionnaire and the evaluation of the face validity and test-retest reliability of its Persian version. Iran J Ergon. 2015;3(3):21-9.

31. Harris SA, Nicolai LA. Occupational exposures in emergency medical service providers and knowledge of and compliance with universal precautions. Am J Infect Control. 2010;38(2):86-94. [DOI:10.1016/j.ajic.2009.05.012] [PMID]

32. Bohström D, Carlström E, Sjöström N. Managing stress in prehospital care: Strategies used by ambulance nurses. Int Emerg Nurs. 2017;32:28-33. [DOI:10.1016/j.ienj.2016.08.004] [PMID]

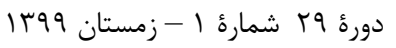


33. Dadashzadeh A, Rahmani A, Hasankhani H, Elmi S. Work related burden of stress among emergency medical service personnel. Iran J Emerg Med. 2018;5:2.

34. Nasiry Zarrin Ghabaee D, Haresabadi M, Bagheri Nesami M, Esmaeili R, Talebpour Amiri F. Musculoskeletal disorders in nurses and their relationship with occupation-related stress. Journal of Mazandaran Uni Med Sci. 2016;25(132):91-102.

35. Davis KG, Kotowski SE. Prevalence of musculoskeletal disorders for nurses in hospitals, long-term care facilities, and home health care: a comprehensive review. Hum Fact. 2015;57(5):75492. [DOI:10.1177/0018720815581933] [PMID]

36. Habibi E, Aganasb M, Ardudar Z, Farrokhi E, Kuhnavard B, Mohammadi Far A. Evaluation of risk of musculoskeletal disorders in hospital wards using MAPO index. J Health Sys Res. 2016;12(3).

37. Nasiry Zarrin Ghabaee D, Haresabadi M, Bagheri Nesami M, Talebpour Amiri F. Work-Related Musculoskeletal Disorders and Their Relationships with the Quality of Life in Nurses. J Ergon. 2016;4(1):39-46. [DOI:10.21859/joe-04015] 